\title{
PENGELOLAAN KEUANGAN KELUARGA SECARA ISLAM PADA KELUARGA MUSLIM ETNIS PADANG DAN MAKASSAR DI SURABAYA 1
}

\author{
Rosalia Debby Endrianti \\ Program Studi S1 Ekonomi Islam - Fakultas Ekonomi dan Bisnis-Universitas Airlangga \\ Email: rosaliadebbye@rocketmail.com \\ Nisful Laila \\ Departemen Ekonomi Islam - Fakultas Ekonomi dan Bisnis - Universitas Airlangga \\ Email: nisful.laila@gmail.com
}

\begin{abstract}
:
The goal of this research is understanding how does management financial implementation work into Muslim Family, especially at Padang and Makassar ethnics in Surabaya.

This research used descriptive qualitative approach. Data collection was resulted by interview, observation, and documentation. Domain and taxonomy technique was used to perform data analytic. This technique to find the general description of financial management family work into Muslim then elaborated more detail to know the internal structure of Islamic view of wealth, the provision, determine the priority scale, and make budget household.

The results based on interviews with two informants from the Padang and Makassar is both informants in research has implemented most components financial management to reach sakinah finance in the life daily. The financial management component are Islamic view of wealth, the provision, determine the priority scale, and make budget household.
\end{abstract}

Keywords: sakinah finance, family, management, finance

\section{I.PENDAHULUAN}

Islam adalah agama yang
komprehensif dan universal yang mengatur seluruh aspek kehidupan, baik kehidupan pribadi, sosial, spiritual dan materialistis serta kehidupan setelahnya (akhirat). Kehidupan yang Islami perlu diaplikasikan pada setiap aspek kehiduapan termasuk di dalamnya adalah kegiatan perekonomian kelvarga.

Salah satu elemen utama dalam kegiatan perekonomian keluarga adalah pengelolaan keuangan. Pengelolaan keuangan pribadi dan keluarga dalam Islam sendiri bisa disebut dengan Sakinah Finance. Pengelolaan keuangan keluarga sangat penting bagi kesejahteraan setiap individu dan keluarga dalam kehidupan sehari-hari.

Inti dari pengelolaan keuangan Islami adalah pengelolaan dengan menentukan skala prioritas dan anggaran belanja rumah tangga. Ajaran Islam mendesak muslim untuk mengelola keuangan sesuai dengan ajaran Allah untuk memastikan kesuksesan dalam hidup.

Sebuah keluarga muslim dalam mengelola pembelajaan pada dasarnya harus berprinsip pada pola konsumsi Islami, yaitu berorientasi kepada kebutuhan (need) serta mendahulukan

1) Jurnal ini merupakan bagian dari skripsi Rosalia Debby Endrianti, NIM : 041114037 , yang diuji pada tanggal 11 Februari 2016. 
Endrianti, et al/Jurnal Ekonomi Syariah Teori dan Terapan Vol. 3 No. 7 Juli 2016: 549-560; PENGELOLAAN KEUANGAN KELUARGA SECARA ISLAM PADA KELUARGA MUSLIMETNIS PADANG DAN MAKASSAR DI SURABAYA

manfaat (utility) dan berusaha mengurangi keinginan yang berlebihan.

Pemilihan etnis Padang sebagai salah obyek yang diteliti didasarkan pada fakta bahwa etnis Padang merupakan etnis perantau terbanyak yang ada di Indonesia. Sedangkan etnis Makassar dipilih sebagai obyek pembanding karena etnis ini juga merupakan perantauan yang memiliki karakteristik unik, seperti kemauan bekerja keras, kebiasaan hidup berhemat, dan kemampuan bertahan dalam situasi sulit.

Kebudayaan merupakan unsur penting dalam proses pembangunan atau keberlanjutan suatu bangsa.

Rumusan masalah dalam penelitian ini adalah bagaimana implementasi pengelolaan keuangan keluarga secara Islam pada keluarga muslim etnis Padang dan Makassar di Surabaya.

Adapun tujuan dari penelitian ini sendiri adalah untuk mengetahui bagaimana implementasi pengelolaan kevangan keluarga secara Islam pada keluarga muslim etnis Padang dan Makassar di Surabaya.

\section{II.LANDASAN TEORI}

Sakinah berasal dari kata "taskunu" yang diambil dari kata "sakana" yakni diam, tenang setelah sebelumnya goncang dan sibuk. Sakinah bisa diartikan juga sebagai kondisi ketenangan yang menjadi ciri utama dari sebuah kehidupan keluarga. Sedangkan Finance adalah segala sesuatu atau aktivitas yang berkaitan dengan vang. Uang adalah salah satu alat bayar yang sah. Fungsi dari uang adalah untuk mengumpulkan kekayaan dan juga sebagai sarana untuk berjaga-jaga (Massasy dalam Rhodiyah, 2012:20).

Garman dan Forgue dalam Personal Finance (2010:4) menyatakan bahwa bagaimana seseorang mengeluarkan, menyimpan,melindungi serta menginvestasikan sumberdaya keuangan mereka merupakan bagian dari finance itu sendiri.

Berdasarkan definisi diatas, sakinah finance merupakan suatu keadaan keuangan yang menenangkan suatu kelvarga, yang didapat secara halal dan dikelola dengan cara yang baik. Sehingga membuat keluarga yang menggunakannya menjadi keluarga yang diberkahi oleh Allah Azza wa Jalla dalam pemanfaatan harta kekayaan.

Pengelolaan keuangan keluarga secara Islam sangat dibutuhkan agar tercapainya sakinah finance. Ada beberapa poin yang harus kita ketahui terlebih dahulu sebelum mengelola keuangan keluarga secara Islam. Diantaranya kita harus mengetahui pandangan Islam tentang harta benda, proses untuk mendapatkan rezeki, menentukan skala prioritas, dan membuat anggaran belanja rumah tangga (Ridha, 2014:180).

Harta adalah segala sesuatu yang dapat disimpan yang dapat digunakan ketika dibutuhkan. Menurut sebagian 
Endrianti, et al/Jurnal Ekonomi Syariah Teori dan Terapan Vol. 3 No. 7 Juli 2016: 549-560; PENGELOLAAN KEUANGAN KELUARGA SECARA ISLAM PADA KELUARGA MUSLIMETNIS PADANG DAN MAKASSAR DI SURABAYA

ulama harta adalah sesuatu yang diinginkan manusia berdasarkan tabiatnya, baik manusia itu akan memberikannya atau akan menyimpannya.

Ada beberapa pandangan Islam tentang harta benda, diantaranya yaitu:

a. Harta merupakan cobaan

b. Harta yang kita miliki sebenarnya milik Allah, kita hanyalah sebagai pengemban amanat.

c. Mempergunakan harta secara bijak dan disertai penuh kedermawanan.

d. Harta yang halal itu baik dan jumlahnya tak terbatas

e. Harta yang haram itu kotor dan jumlahnya terbatas (harta anak yatim, harta riba, memakan harta orang lain dengan tidak benar, makan harta haram, harta yang dapat melalaikan dari zikir kepada Alah, menafkahkan harta di jalan Allah dapat mengembangbiakkan harta itu sendiri, di dalam harta ada hak bagi orang lain, harta benda bukanlah bekal di akhirat, harta dapat menjadi sarana untuk menyelamatkan diri di akhirat).

Jaminan rezeki memberikan pengertian Allah akan selalu memenuhi kebutuhan kita, kapan pun dan dimana pun, sehingga kita benar-benar yakin bahwa Allah Dialah Maha Pemberi rezeki.

Akan tetapi, Allah telah menciptakan berbagai sarana atau sebab untuk mendapatkan rezeki dan bahkan Allah telah menciptakan segala sesuatu itu pasti ada penyebabnya. Ada banyak sekali sarana yang dapat mendatangkan rezeki dan membuatnya sangat mudah untuk dicapai serta penuh dengan limpahan berkah.

Sarana rezeki dapat digolongkan menjadi dua sarana pokok, yaitu tawakal yang sejati dan berusaha secara maksimal.

a. Tawakal Sejati (Keimanan dan Ketakwaan, Istighfar, doa dan zikir, bersyukur dan bersabar, berinfaq di jalan Allah, silaturahim).

b. Berusaha secara maksimal (niat, membuat perencanaan, tekun dan progresif, tawazun).

Skala prioritas adalah mengerjakan sesuatu yang paling penting terlebih dahulu, kemudian yang penting, agak penting, lantas yang kurang penting.

Sementara, menentukan skala prioritas adalah meletakkan segala sesuatu secara proporsional. Tidak mengakhirkan sesuatu yang seharusnya didahulukan, atau mendahulukan sesuatu yang seharusnya diakhirkan. Tidak menganggap kecil sesuatu yang besar atau menganggap besar sesuatu yang kecil.

Secara garis besar, para ulama telah membagi skala prioritas ke dalam tiga bagian:

1. Kebutuhan Primer

2. Kebutuhan Sekunder

3. Kebutuhan Tersier

Anggaran belanja adalah upaya untuk menyeimbangkan atau meluruskan dua sisi timbangan antara pemasukan dan pengeluaran. 
Endrianti, et al/Jurnal Ekonomi Syariah Teori dan Terapan Vol. 3 No. 7 Juli 2016: 549-560; PENGELOLAAN KEUANGAN KELUARGA SECARA ISLAM PADA KELUARGA MUSLIMETNIS PADANG DAN MAKASSAR DI SURABAYA

Diantara syaratnya adalah :

1. Harus disesuaikan dengan jangka waktu tertentu.

2. Harus diketahui surplusnya jika memang ada, lalu menentukan bagaimana cara mengelola dan menginvestasikannya.

3. Harus diketahui defisitnya jika memang ada, lalu mengupayakan bagaimana cara menutupinya.

Sebelum melakukan pengelolaan kevangan keluarga secara Islam, harus mengetahui pandangan Islam tentang harta benda itu sendiri, proses mendapatkan rezeki, setelah itu baru menentukan skala prioritas dan membuat anggaran belanja rumah tangga.

Pengelolaan keuangan keluarga secara Islam tidak hanya sekedar proses mengelola kekayaan semata,tapi juga memiliki definisi yang luas berkaitan dengan tugas manusia sebagai khalifah untuk memanfaatkan nikmat Allah Azza wa Jalla di muka bumi mengikuti aturanaturan syariah Islam.

\section{Pengelolaan}

keluargasecara Islam

keuangan

seseorang untuk mendapatkan gambaran pengelolaan keuangan kelvarga yang diinginkan ditiap tahapan kehidupan, melindungi aset-aset yang dimiliki, mempergunakan utang secara hati-hati, melakukan manajemen resiko dan melatih seseorang untuk mengatur risiko investasi dengan baik, menentukan asuransi perlindungan yang tepat untuk jiwa, kesehatan, dan harta kepemilikan, meningkatkan kekayaan, serta mengontrol pengeluaran dan biayabiaya.

Hal-hal utama yang termasuk dalam pengelolaan kevangan keluarga secara Islam adalah pandangan Islam tentang harta benda, proses mendapatkan rezeki,menentukan skala prioritas, serta membuat anggaran belanja rumah tangga.

\section{III.METODE PENELITIAN}

Pendekatan penelitian yang digunakan dalam penelitian ini adalah pendekatan kualitatif. Pendekatan kualitatif adalah pendekatan dengan menggunakan data yang berupa kalimat tertulis atau lisan, peristiwa-peristiwa, pengetahuan, atau proyek studi yang bersifat deskriptif (Nazir, 2003:54).

Tujuan dari penelitian ini adalah untuk menjawab rumusan masalah mengenai bagaimana implementasi pengelolaan keuangan secara Islam pada keluarga muslim. Pertanyaan 'bagaimana' lebih tepat menggunakan pendekatan kualitatif karena dalam penelitian ini peneliti tidak memiliki peluang untuk melakukan kontrol terhadap obyek penelitian.

Penelitian ini juga menggunakan penelitian kualitatif deskriptif. Alasan lain penggunaan metode penelitian kualitatif deskriptif pada penelitian ini adalah penelitian ini tidak bertujuan melakukan uji hipotesis dengan metode statistik atau ekonometri.

Strategi yang digunakan dalam penelitian ini adalah studi kasus, karena 
Endrianti, et al/Jurnal Ekonomi Syariah Teori dan Terapan Vol. 3 No. 7 Juli 2016: 549-560; PENGELOLAAN KEUANGAN KELUARGA SECARA ISLAM PADA KELUARGA MUSLIMETNIS PADANG DAN MAKASSAR DI SURABAYA

menyelidiki fenomena dalam konteks kehidupan masyarakat (nyata), sehingga menggunakan multi sumber bukti dimanfaatkan, yaitu bila batas-batas antara fenomena dan konteks tak tampak dengan tegas. Penelitian ini juga menggunakan studi kepustakaan sebagai pendukung karena penelitian ini membutuhkan studi pendahuluan (prelimanry research) untuk memahami lebih dalam gejala baru yang tengah berkembang di dalam masyarakat. Selain itu data pustaka merupakan data yang andal untuk menjawab persoalan penelitian ini.

\section{Ruang Lingkup Penelitian}

Ruang lingkup penelitian ini terbatas pada keluarga muslim etnis Padang dan Etnis Makassar yang diwakili oleh pasangan suami istri. Kriteria selanjutnya adalah 1 pasangan tersebut minimal sudah memiliki satu anak, hal tersebut dipilih karena dengan mempunyai anak, suatu pasangan akan lebih mengelola keuangan keluarga secara baik karena mempertimbangkan masa depan anaknya. Informan dalam penelitian ini didapatkan dengan menggunakan purposive sampling yakni teknik pengambilan sampel sumber data dengan pertimbangan kriteria tertentu. Pertimbangan kriteria tertentu ini adalah keluarga muslim, minimal memiliki satu orang anak yang berasal dari etnis Padang dan Makassar.

\section{Jenis dan Sumber Data}

Dalam penelitian kualitatif data yang dibutuhkan ada dua jenis, yaitu primer (utama) dan sekunder (tambahan atau penunjang).

a. Data primer

Data yang diperoleh berasal dari hasil observasi dan wawancara di lapangan. Data ini diperoleh melalui observasi dan wawancara pada informan. Data Primer dalam penelitian ini adalah keluarga muslim etnis Padang dan Makassar dan minimal memiliki satu orang anak dan memiliki pencatatan kevangan. Penelitian ini diwakili masing-masing oleh satu pasangan suami istri etnis Padang dan Makassar.

Kelvarga pertama adalah kelvarga beretnis Padang yang diwakili oleh wirausahawan penjual nasi padang yang memiliki 3 orang anak, alasan penulis memilih keluarga ini, karena keluarga ini perantauan dari Padang dan berhasil sukses menghidupi 3 orang anak dan satu istrinya, serta mampu mempunyai rumah dari hasil kerja kerasnya .

Kelvarga kedua adalah keluarga beretnis Makassar, keluarga ini diwakili oleh wirausahawan juga yang berjualan sop konro Makassar, memiliki 2 orang anak, istrinya beretnis Jawa. Kelvarga ini dipilih karena penulismelihat ada percampuran budaya dalam keluarga tersebut yaitu Makassar dan Jawa. Kelvarga ini juga merupakan perantauan yang sukses menghidupi 2 orang anak 
Endrianti, et al/Jurnal Ekonomi Syariah Teori dan Terapan Vol. 3 No. 7 Juli 2016: 549-560; PENGELOLAAN KEUANGAN KELUARGA SECARA ISLAM PADA KELUARGA MUSLIMETNIS PADANG DAN MAKASSAR DI SURABAYA

serta mampu membeli rumah atas kerja kerasnya.

b. Data sekunder

Data yang diperoleh dari suatu objek penelitian yang berupa pecatatan keuangan yang dimiliki oleh masingmasing kelvarga muslim etnis Padang dan Makassar.

\section{Teknik Pengumpulan Data}

Teknik pengumpulan data yang digunakan dalam penelitian ini adalah:.

a. Wawancara/ interview

Penelitian ini menggunakan wawancara terstruktur dimana peneliti telah menyiapkan instrumen penelitian berupa pertanyaan-pertanyaan tertulis. Wawancara terstruktur ini, informan diberi pertanyaan yang sama dan peneliti mencatatnya. Wawancara ini ditujukan kepada suami istri keluarga muslim etnis Padang dan Makassar. Informan dari penelitian ini adalah satu keluarga muslim etnis Padang yang terdiri dari suami dan istri, dan satu keluarga etnis Makassar yang terdiri dari suami dan istri.

b. Dokumentasi

Dokumentasi dalam penelitian ini adalah bukti berupa laporan keuangan keluarga muslim tersebut.

\section{Unit Analisis}

Unit analisis dalam penelitian ini adalah:

1. Bagaimana pandangan tentang harta benda pada keluarga muslim etnis Padang dan Makassar-Jawa.
2. Bagaimana proses mendapatkan rezeki kelvarga muslim etnis Padang dan Makassar-Jawa.

3. Bagaimana menentukan skala prioritas keluarga muslim etnis Padang dan etnis Makassar-Jawa.

4. Bagaimana membuat anggaran belanja rumah tangga pada keluarga muslim etnis Padang dan etnis MakassarJawa.

\section{Teknik Validasi}

Penelitian ini menggunakan trianggulasi sumber data dan trianggulasi teori, trianggulasi sumber data diambil dengan cara mewawancarai suami dan istri etnis Padang dan suami istri etnis Makassar dan mendokumentasikan pencatatan keuangan keluarga tersebut. Trianggulasi teori dengan cara membandingkan penelitian dengan teori yang ada.

\section{Teknik Analisis Data}

Teknik analisis dalam penelitian ini adalah:

a. Teknik analisis domain. Teknik analisis domain digunakan untuk memperoleh gambaran umum mengenai implementasi pengelolaan keuangan secara Islampada keluarga muslim etnis Padang dan Makassar di Surabaya

b. Teknik analisis taksonomi. Teknik analisis ini digunakan untuk memperoleh gambaran mengenai pandangan Islam tentang harta benda, proses mendapatkan rezeki, menentukan 
Endrianti, et al/Jurnal Ekonomi Syariah Teori dan Terapan Vol. 3 No. 7 Juli 2016: 549-560; PENGELOLAAN KEUANGAN KELUARGA SECARA ISLAM PADA KELUARGA MUSLIMETNIS PADANG DAN MAKASSAR DI SURABAYA

skala prioritas, serta membuat anggaran belanja rumah tangga.

\section{IV.HASIL DAN PEMBAHASAN}

\section{Gambaran Umum Subjek Penelitian}

Informan pertama, yakni keluarga muslim etnis Padang merupakan sepasang suami istri yang sudah menikah sejak tahun 1996 serta telah memiliki 3 orang anak. Sang kepala keluarga, yaitu Bapak Djoni bekerja sebagai wirausaha penjual nasi padang. Sedangkan Ibu Kiki (istri Bapak Djoni) adalah seorang ibu rumah tangga dan membantu pak Djoni berjualan nasi padang. Penghasilan ratarata keluarga ini sebulan sebesar Rp. 45.000.000,-

Informan kedua adalah pasangan suami istri beretnis Makassar (Bapak Hamka) dan Jawa (Ibu Yoana). Pasangan ini telah menikah sejak tahun 2007 dan dikarunia 2 orang anak.Pekerjaan Bapak Hamka saat ini adalah mengelola rumah makan sop konro makassar milik ibu nya di Tanjung Perak Surabaya. Sedangkan Ibu Yoana bekerja di Bank BRI. Penghasilan rata-rata keluarga ini sebulan sebesar Rp. 22.000.000,-

\section{Deskripsi Hasil Penelitian}

Peneliti membagi hasil penelitian menjadi empat bagian dalam pengelompokan pengelolaan keuangan keluarga, yaitu pandangan Islam tentang harta benda, proses mendapatkan rezeki, menentukan skala prioritas, serta membuat anggaran belanja rumah tangga.

\section{a. Pandangan Islam tentang Harta Benda}

Bapak Djoni bekerja sebagai wirausaha penjal nasi padang memandang Harta benda bisa menjadi cobaan jika tidak bisa mengelola nya dengan baik. Akan cepat habis harta itu jika tidak bisa mengaturnya dengan baik. Allah memberi cobaan untuk memiliki harta yang banyak kemudian bisa dilihat apakah harta itu bisa dikelola dengan baik atau tidak. Harta hanya titipan Allah, kita hanya sebagai hamba nya yang mempergunakan harta itu dengan baik.

Bapak Hamka bekerja sebagai pengelola rumah makan sop konro makassar milik ibu nya di Tanjung Perak Surabaya memandang harta hanya titipandari Allah, dan bukanmerupakan segalanya.

\section{b. Proses Mendapatkan Rezeki}

Salah satu proses mendapatkan rezeki adalah bertawakal kepada Allah. Selalu bersyukur dengan apa yang diberikan Allah kepada umatnya. Selalu bersabar dengan cobaan apa yang Allah berikan kepada umatnya. Serta dengan niat awal kita dalam mencari rezeki di jalan Allah.

.Keluarga Bapak Djoni
mengatakan salah satu proses
mendapatkan rezeki adalah selalu
bertawakal di jalan Allah mbak. Selain
itu harus selalu berusaha dan berdoa
dalam setiap perbuatan, harus
bersyukur dengan apa yang diberikan


Allah kepada kita. Selalu bersabar jika diberikan cobaan oleh Allah, dan yang paling penting adalah bertawakal kepada Allah, insyallah rezeki akan mengalir. Allah juga sudah menyediakan rezeki kepada setiap umatnya, jadi kita tidak perlu khawatir

Proses mendapatkan rezeki menurut Bapak Hamka adalahsatu cara mendapatkan rezeki adalah dengan selalu bertawakal kepada Allah. Selalu bersyukur dengan apa yang diberikan Allah. Selalu bersabar jika mendapatkan cobaan dari Allah. Selalu berinfaq di jalan Allah serta selalu menjaga tali silaturahmi. Juga tidak lupa sarana mendapatkan rezeki adalah dengan usaha yang maksimal. Diawali dengan adanya niat, perencanaan yang matang, selalu tekun dalam melaksanakan segala hal, serta tawazun (keseimbangan antara di dunia dan di akhirat). Itulah sarana dalam mendapatkan rezeki dari Allah.

\section{c. Menentukan Skala Prioritas}

Sebuah keluarga penting untuk menentukan skala prioritas guna mengelola keuangan keluarga agar berjalan sesuai dengan apa yang diinginkan oleh keluarga.

Bapak Djoni mengatakan bahwa Skala prioritas yang didahulukan adalah kebutuhan primer. Pendapatan yang saya dapat dari berjualan nasi padangdigunakan untuk pendidikan anak, membayar gaji pegawai, berbelanja keperluan berjualan nasi padang, membayar tagihan air listrik telepon, berzakat tiap bulan. Jadi yang didahulukan yang penting dulu. Baru sisanya akan ditabung untuk keperluan yang tidak terduga. Semua sudah direncanakan.

Bapak Hamka mengatakan bahwa penentuan skala prioritas dengan mendahulukan kebutuhan primer. Biaya pendidikan anak-anak, biaya belanja setiap hari, membayar asisten rumah tangga, membayar tagihan listrik air telepon, berzakat setiap bulan, ditabung, dan untuk biaya-biaya tidak terduga, beli susu anak juga penting kemudian setiap akhir pekan, anak-anak minta bermain di mall.

\section{d. Membuat Anggaran Belanja Rumah Tangga}

Membuat anggaran belanja di dalam keluarga menjadi sangat penting untuk mengelola keuangan keluarga. Keluarga Bapak Djoni membuat anggaran belanja rumah tangga untuk kebutuhan primer. Pendapatan dari penjualan nasi padang dikurangi untuk kebutuhan primer.

Mulai dari biaya pendidikan anakanak, belanja untuk keperluan berjualan nasi padang, membayar gaji pegawai, membayar tagihan listrik air telepon, untuk zakat.

Anggaran belanja harus disesuaikan dengan waktu tertentu. 
Endrianti, et al/Jurnal Ekonomi Syariah Teori dan Terapan Vol. 3 No. 7 Juli 2016: 549-560; PENGELOLAAN KEUANGAN KELUARGA SECARA ISLAM PADA KELUARGA MUSLIMETNIS PADANG DAN MAKASSAR DI SURABAYA

Jika terjadi surplus anggaran belanja maka bagaimana caranya untuk mengelola dan menginvestasikan. Jika terjadi deficit, bagaimana cara menutupinya. Jika penjualan sepi, terkadang bisa deficit mbak.

Kelvarga Bapak Hamka membuat anggaran belanja rumah tangga untuk kebutuhan primer. Pendapatan yang diperoleh dari membantu ibu saya mengelola rumah makan sop konro di Tanjung perak, dikelola untuk memenuhi kebutuhan sehari-hari. Mulai dari biaya pendidikan anakanak, membayar tagihan listrik air telpon, membayar gaji asisten rumah tangga, zakat. Jika terdapat surplus, maka akan ditabung dan diinvestasikan pada rumah. Berbeda dengan pendapatan istri saya ibu Yoana yang langsung dipotong zakat, dipotong pinjaman di kantor, lalu sisanya ditabung. Atau bisa untuk biaya yang tidak terduga seperti perawatan mobil dan renovasi rumah.

\section{V.SIMPULAN}

Informan dalam penelitian telah menerapkan sebagian besar komponen pengelolaan keuangan untuk mencapai sakinah finance dalam kehidupan sehariharinya. Komponen pengelolaan keuangan tersebut adalah pandangan Islam tentang harta benda, sarana mendapatkan rezeki, menentukan skala prioritas, membuat anggaran belanja rumah tangga.
Kelvarga pertama dengan latar belakang etnis Padang dan keluarga kedua dengan latar belakang etnis makassar sama-sama telah menerapkan sebagian besar dari komponen pengelolaan keuangan yaitu memandang harta milik Allah, manusia hanya sebagai pengemban amanat, memperoleh rezeki dengan cara bertawakal sejati dengan cara selalu beristighfar, berdoa dan berzikir kepada Allah, berinfaq di jalan Allah, menjaga silaturahmi serta berusaha yang maksimal dengan niat, perencanaan yang matang, tekun dan progresif, bertawazun (keseimbangan antara hidup di dunia dan di akhirat), menentukan skala prioritas dimulai dari kebutuhan primer dan membayar zakat. Serta membuat anggaran belanja rumah tangga, jika terdapat surplus akan ditabung.Jika deficit maka akan dicari bagaimana cara menutupinya. Serta mengimplementasikan komponen kevangan dana emergensi seperti investasi dengan melakukan pembelian rumah yang diangsur di bank.

Perbedaannya terletak pada, keluarga pertama hidup lebih sederhana dibandingkan dengan keluarga kedua. Meskipun pendapatan dari keluarga pertama lebih banyak dibandingkan dengan pendapatan keluarga kedua, keluarga pertama jauh lebih hemat dan sederhana.

Kelvarga pertama jika terdapat surplus anggaran belanja maka akan 
Endrianti, et al/Jurnal Ekonomi Syariah Teori dan Terapan Vol. 3 No. 7 Juli 2016: 549-560; PENGELOLAAN KEUANGAN KELUARGA SECARA ISLAM PADA KELUARGA MUSLIMETNIS PADANG DAN MAKASSAR DI SURABAYA

ditabung. Berbeda dengan keluarga kedua, memang jika terdapat surplus akan ditabung juga. Tetapi keluarga kedua mempunyai hutang pada kartu kredit sehingga terlihat tidak seberapa hemat seperti keluarga pertama.

Keluarga pertama jarang sekali melakukan liburan diluar rumah, makan malam diluar saja hanya sesekali. Sedangkan pada keluarga kedua mempunyai kartu kredit yang setiap minggunya digunakan oeh keluarga kedua untuk berbelanja di mall bersama anaknya. Itulah yang membedakan antara kedua keluarga tersebut.

\section{SARAN}

Saran yang diberikan penulis adalah:

1. Saran untuk pemerintah

Memberikan pelatihan atau sosialisasi kepada pasangan suami istri dalam rangka mengelola kevangan keluarga yang sesuai dengan Islam.

2. Saran untuk penelitian selanjutnya:

a. Penelitian tentang pengelolaan kevangan keluarga secara Islam perlu dilakukan dengan metode yang berbeda untuk mendapatkan gambaran tentang sakinah finance secara lebih bervariasi.

b. Membuat penelitian baru yang memuat informan yang berasal dari berbagai macam suku sehingga memiliki data yang beragam dan bervariasi.

\section{Daftar Pustaka}

Amalina, Abdullah \& Muhammad Junaina. Ethnical Values in Islamic Planning (Nilai-nilai Etika dalam Rancangan Kewangan Islam). Jurnal Pengurusan 38(2013) 133 - 140. Faculty of Economics and Management, Universiti Putra Malaysia.

Al-Qur'an. Terjemahannya (Revisi terbaru) Departemen Agama RI dengan transletisasi Arab-Latin. 2001. Semarang: CV. Asy Syifa.

Antonio, Muhammad Syafi'i. 2001. Bank Syariah Dari Teori Ke Praktik. Jakarta: Gema Insani Press.

Antonio, Muhammad Syafi'i. 2011. Ensiklopedia Leadership dan Manajemen Muhammad SAW "The Super Leader Super Manager" Bisnis dan Kewirausahaan. Jakarta : Tazkia Publishing.

Asyahidah, Karimah. 2014. Implementasi Sakinah Finance pada keluarga Muslim IStudi Kasus Dua Keluarga Dalam Tionghoa dan jawa di Surabaya). Fakultas Ekonomi dan Bisnis Universitas Airlangga.

Fajri, Rahmat. 2008. Sejarah Keuangan Islam. Jurnal Aplikasi IImu-ilmu Agama. Vol. IX. No. 2

Garman, E. Thomas dan Raymond E Forgue. 2010. Personal Finance. Mason: South-Western Cengage Learning. 
Endrianti, et al/Jurnal Ekonomi Syariah Teori dan Terapan Vol. 3 No. 7 Juli 2016: 549-560; PENGELOLAAN KEUANGAN KELUARGA SECARA ISLAM PADA KELUARGA MUSLIMETNIS PADANG DAN MAKASSAR DI SURABAYA

Hidayat, Mohamad. 2010. An Introduction to The Sharia Economic. Jakarta: Zikrul Hakim.

Hikmah, Rosmarul. 2003. Etos Kerja Pedagang Perantau Minangkabau Dalam Perspektif Nilai Budaya Minangkabau. Skripsi. Fakultas Keguruan Dan IImu Pendidikan Universitas Sebelas Maret Surakarta

Ika S, Ardiani. 2011. Personality Traits sebagai Penentu Perencanaan Keuangan Keluarga (Suatu Kajian Pustaka). Semarang. Fakultas Ekonomi Universitas Semarang.

Manurung, Adier. 2009. Succesfull financial planner : A complete Guide. Jakarta: Grasindo.

Munir, Misnal. 2012. Hidup di Rantau Dengan Damai: Nilai-Nilai Kehidupan Orang Minangkabau Dalam Menyesuaikan Diri Dengan Lingkungan Budaya Baru. International Conference On Indonesian Studies: "Etnicity And Globalization".

Nafik, Muhammad. 2009. Bursa Efek dan Investasi Syariah. Jakarta: PT. Serambi IImu Semesta

Nazir, Moch. 2003. Metode Penelitian. Jakarta : Salemba empat

Nurannisa, Andi. 2014. Dinamika Kelompok Masyarakat Perantau Kasus Anggota Kerukunan Keluarga Sulawesi Selatan (Kkss) Rumpun Siparappe Di Kota Baubau. Skripsi diterbitkan. Fakultas IImu Sosial Dan IImu Politik Universitas Hasanuddin Makassar.
Pusat Pengkajian dan Pengembangan Ekonomi Islam. 2008. Ekonomi Islam. Jakarta: Rajawali Pers.

Ridha, Akram. 2014. Pintar Mengelola Kevangan Keluarga Sakinah : Mudah dan Sesuai Kaidah Islam. Solo : Tayiba Media.

Rhodiyah. 2012. Manajemen Keuangan Kelvarga Guna Menuju Keluarga Sejahtera. Jurnal Topik Utama.

Shihab, Quraish. 2005. Tafsir Al-Mishbah Pesan, Kesan dan Keserasian Al-Qur'an. Jakarta: Lentera Hati

Sugiyono. 2011. Metode Penelitian Kuantitatif dan Kualitatif. Bandung: Alfabeta

Sugiyono. 2013. Memahami Penelitian Kualitatif. Bandung : Alfabeta.

Suhartini, Dwi\& Jefta A. R. Pengelolaan Kevangan Keluarga Pedagang Etnis Cina. Jurnal Riset Ekonomi dan Bisnis Volume 7 No 2 September 2007. Universitas Pembangunan Nasional Surabaya.

Suhendi, Hendi. 2011. Fiqh Muamalah. Jakarta: Raja Grafindo Persada.

Tamanni, Luqyan dan Murniati Mukhlisin. Sakinah Finance. 2013. Solo: Tinta Medina.

Yin, Robert K. 2009. Case Study Research: Design and Methods. Applied social research methods series. Volume 5.

Yin, Robert K. 2012. Application Case Study Research: Design and Methods. Applied social research methods series. Volume 5. 
Endrianti, et al/Jurnal Ekonomi Syariah Teori dan Terapan Vol. 3 No. 7 Juli 2016: 549-560; PENGELOLAAN KEUANGAN KELUARGA SECARA ISLAM PADA KELUARGA MUSLIMETNIS PADANG DAN MAKASSAR DI SURABAYA

Yohnson. 2004. Universitas di Surabaya dalam Meningkatkan Jumlah Kelvarga Mapan di Surabaya (Seri Penelitian Keuangan Keluarga). Fakultas Ekonomi Juruan Manajemen, Universitas Kristen Petra. 